\title{
A Argumentação dos Deputados na Votação do Processo de Impeachment de Dilma Rousseff
}

\author{
Felipe Bonow Soares \& Raquel Recuero \\ Universidade Federal do Rio Grande do Sul, Brasil \\ E-mail: felipebsoares@hotmail.com/raquelrecuero@gmail.com
}

\begin{abstract}
Resumo
Este estudo busca analisar os argumentos utilizados pelos deputados federais brasileiros na primeira votação do processo de impeachment de Dilma Rousseff, em abril de 2016. A proposta é realizar uma análise ancorada em três bases: a análise de con-

teúdo, a análise de redes e a análise argumentativa. O que se pretende descobrir é como argumentaram os deputados e quais as diferenças discursivas podem ser observadas entre os que votaram a favor e os que votaram contra o processo.
\end{abstract}

Palavras-chave: análise argumentativa; análise de conteúdo; análise de redes; impeachment; política.

\begin{abstract}
This study seeks to analyze the arguments used by Brazilian federal deputies in the first voting of Dilma Rousseff's impeachment in April 2016. The proposal is to perform an analysis anchored on three bases:

tive analysis. It is intended to discover how the deputies argued and which are the discursive differences observed among those who voted for and who voted against the process.
\end{abstract} a content analysis, network analysis and argumenta-

Keywords: argumentative analysis; content analysis; network analysis; impeachment; politics.

\section{INTRODUÇÃO}

$\mathrm{T}^{\mathrm{M}}$ dos fatos mais importantes da história política do Brasil deu-se no ano de 2016, quando o processo de impeachment da presidenta Dilma Rousseff (PT - Partido dos Trabalhadores) aconteceu no Congresso Nacional. O processo, o segundo a ser instaurado no País em sua história democrática, foi repleto de controvérsias, que puderam ser percebidas pelos discursos dos parlamentares envolvidos, pela cobertura da mídia e mesmo pelas inúmeras manifestações contrárias e favoráveis que apareceram nas ruas.

Data de submissão: 2017-12-26. Data de aprovação: 2018-04-26.

A Revista Estudos em Comunicação é financiada por Fundos FEDER através do Programa Operacional Factores de Competitividade - COMPETE e por Fundos Nacionais através da FCT - Fundação para a Ciência e a Tecnologia no âmbito do projeto Comunicação, Filosofia e Humanidades (LabCom.IFP) UID/CCI/00661/2013.
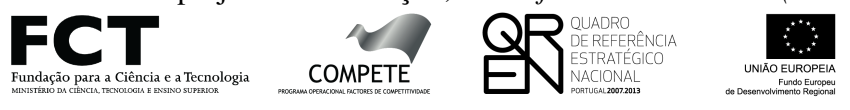

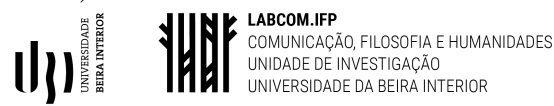


Neste trabalho, pretendemos explorar os sentidos dos discursos proferidos pelos deputados que votaram o impeachment de Dilma Rousseff, evento ocorrido no dia 17 de abril de 2016, na Câmara de Deputados, com transmissão ao vivo pela televisão e outros veículos midiáticos. Durante e após a votação, as justificativas dos votos dos deputados foram amplamente divulgadas e causaram ainda mais debates. Assim, o que se pretende é compreender que tipo de argumentos foram majoritariamente utilizados pelos deputados e realizar uma diferenciação entre os que votaram a favor e contra o processo de impeachment e os discursos decorrentes desses posicionamentos, através de uma proposta de análise de dados ancorada em três pontos: Análise de Conteúdo, Análise de Redes e Análise Argumentativa.

Dos 513 membros da câmara de deputados, apenas dois não estavam presentes na data da votação. Eram necessários 342 votos "sim" para que a proposta de impeachment fosse aprovada. Foram 367 votos favoráveis, a proposta seguiu para o senado e teve como conclusão a retirada de Dilma Rousseff do cargo de presidente. A sessão começou às $14 \mathrm{~h}$, a votação teve início às $17 \mathrm{~h} 45$ e durou cerca de seis horas.

\section{Discurso Político e Poder Simbólico}

O discurso político tem sua primeira conceitualização com Aristóteles (Retórica), quando o autor fala sobre o gênero deliberativo. Neste gênero, se enquadram os discursos produzidos no âmbito das decisões políticas tomadas pelos cidadãos das Cidades-estado gregas. Ou seja, o gênero deliberativo está relacionado com processos democráticos. Em um contexto contemporâneo, os cidadãos participam de uma democracia representativa e não mais se reúnem para decidir o futuro da sociedade, como na Grécia Antiga (Fidalgo, 2010). Agora, são os políticos eleitos pelos cidadãos os responsáveis por tomar decisões que envolvem as cidades, estados ou países. A posição de político se tornou uma profissão. Além disso, o debate público se dá em uma sociedade mediatizada e as estratégias e sentidos produzidos nestes espaços são centrais para a compreensão do discurso político (Fidalgo, 2010).

Pensando neste novo contexto, Van Dijk (2002) define que o discurso político é aquele produzido por políticos profissionais em atos políticos. Estes atos podem ser variados, como, por exemplo, quando os políticos realizam campanhas eleitorais em busca de votos; quando legislam, como nas câmaras de vereadores e deputados, por exemplo; quando governam, realizando falas públicas sobre suas decisões; dentre outras situações necessariamente relacionadas com a profissão política. O discurso analisado neste estudo é, portanto, de acordo com esta discussão, um discurso político. Ele é realizado por políticos profissionais, os deputados federais brasileiros; em um ato político, a votação sobre o processo de impeachment de Dilma Rousseff.

De modo geral, os autores da retórica, um dos pilares teóricos deste trabalho, não se preocupam em aprofundar o conceito de discurso. Este é utilizado no mesmo sentido de texto e fala. O discurso, para eles, é apenas o que é dito. Levando em consideração o cenário social atual, definido por Fidalgo (2010) como um sistema mais complexo em que a retórica se torna "mediatizada", entende-se necessário pensar um conceito capaz de identificar aspectos mais amplos nas falas dos deputados. Entretanto, consideraremos, neste trabalho, o discurso como um meio produtor de sentidos, relacionado com a linguagem, mas que vai além do texto ou da fala, levando 
em conta também outros elementos: o orador (quem é, de onde vem, suas ideologias, como é construído pelos outros, como se constrói, suas relações com seu partido e outras instituições), o auditório/público (para quem fala o orador, em que pressupostos são baseados os argumentos, que tipo de linguagem é utilizada), o contexto (em especial o político, mas também os elementos sociais, culturais e históricos que envolvem o discurso produzido), a situação (onde o discurso é produzido, o meio onde está, os interlocutores envolvidos) e as relações entre estes diversos elementos. Estes componentes podem ser encontrados no discurso por meio das marcas verbais que nele se apresentam.

Para Bourdieu (1983), o discurso político está diretamente relacionado com as disputas pelo poder simbólico, dentro de um campo específico, aquele da política. Os discursos políticos fazem parte do processo de produção de sistemas simbólicos que por sua vez, vão justificar as relações de poder através do habitus. O habitus, conceito central no trabalho do autor, é definido como "os sistemas de disposições duráveis, estruturas estruturadas predispostas a funcionarem como estruturas estruturantes" (p.61). O habitus, assim, que guiaria as ações dos sujeitos, é formado pelos sistemas simbólicos construídos socialmente e naturalizados pelo discurso, orquestrando relações individuais. Deste modo, os discursos proferidos pelos deputados têm papel importante na construção dos sistemas de ideias das pessoas e refletem também esse sistema presente na sociedade. Por isso, uma vez desvelado o discurso presente nesses dados, podemos observar os sistemas simbólicos que os deputados utilizaram como justificativa de seu posicionamento, buscando observar as estruturas de poder. Assim, a partir da análise de contingência e de observações específicas é possível identificar esses sistemas nas falas produzidas pelos deputados na situação analisada.

\section{MÉTODO}

A questão a que nos propusemos neste artigo, assim, é compreender o discurso dos deputados em sua votação pela instauração do processo de impeachment. Para tanto, precisamos analisar essas falas e encontrar-lhes regularidades que possam desenhar esse discurso e compreender como os mecanismos da retórica foram utilizados pelos mesmos.

Para dar conta desses elementos, desenhamos um método que compreende uma análise semântica mediada por computador a partir da mixagem da análise de conteúdo (Bardin, 2003) e da análise de redes (vide Recuero, Bastos e Zago, 2015), que busca explorar de modo quantitativo os conceitos mais utilizados pelos deputados e suas relações; e a análise argumentativa, de foco qualitativo, que busca analisar os modos de argumentar destes deputados. Essa proposta parte de um viés quanti-qualitativo, a partir de um formato de métodos mistos.

Ao dar seu voto na Câmara, no dia 17, os deputados encaminhavam-se ao microfone e tinham alguns minutos para declarar sua posição, que foi televisionada para todo o país. Assim, os dados que utilizamos para este trabalho foram essas falas transcritas, que totalizaram os votos de 513 deputados (com 07 abstenções e 02 ausências). Destes votos, 367 foram favoráveis à abertura do processo de impeachment e 137 foram contrários. As falas foram analisadas dentro do seu posicionamento de voto. Assim, buscamos sistematizar o discurso dos votaram os deputados que votaram a favor da abertura do processo e compará-lo com o discurso daqueles que votaram contra. 


\section{Análise de Conteúdo}

Inicialmente, buscamos compreender, através da análise de conteúdo (Bardin, 2003), categorias amplas de léxicos mais utilizados pelos deputados. As palavras utilizadas nas falas foram, assim, contadas através de um software (a chamada análise de frequência), de onde foram retiradas aquelas com menor carga semântica (por exemplo, artigos). Após esta fase, as palavras mais utilizadas (até cinco repetições) foram analisadas em seus contextos e agrupadas em categoriasconceitos mais amplos, de mesmo sentido (por exemplo, "mulher" e "mulheres"). Essas categorias foram, após, contabilizadas pela presença no corpus (quantidade de vezes que cada conceito foi citado por deputados contrários/favoráveis ao processo), de modo a auxiliar a compreender sua importância dentro daquele grupo.

A tabela a seguir (Tabela 1) mostra os quinze conceitos mais frequentes no grupo do "sim" (deputados favoráveis à abertura do processo de impeachment) do no grupo do "não" (deputados contrários). $\mathrm{Na}$ totalidade, foram classificados cerca de 50 conceitos para cada lado.

Tabela 1. Conceitos mais presentes

\begin{tabular}{lclc}
\hline & SIM & & NÃO \\
Conceito & Número de citações & Conceito & Número de citações \\
\hline Voto & 315 & Voto & 106 \\
Brasil & 310 & presidente & 76 \\
Presidente & 259 & democracia & 72 \\
Povo & 245 & Golpe & 52 \\
Estado & 109 & Dilma & 37 \\
Família & 98 & Povo & 36 \\
impeachment & 81 & Brasil & 63 \\
esperança & 49 & Constituição & 33 \\
Dilma & 46 & Impeachment & 30 \\
Respeito & 45 & Defesa & 24 \\
corrupção & 43 & Cunha & 23 \\
Deus & 42 & Respeito & 23 \\
Cidade & 41 & Crime & 22 \\
Futuro & 40 & Temer & 21 \\
deputados & 40 & casa & 21 \\
\hline
\end{tabular}

Nesta tabela já observamos as diferenças nos conceitos mais frequentes utilizados por um lado e por outro. Por exemplo, enquanto no "SIM", os conceitos mais frequentes focam elementos relacionados aos estados dos deputados, suas famílias e Deus, no "NÃO" vemos conceitos de "democracia", "golpe" e "constituição". Veremos na análise deste estudo os contextos em que esses conceitos aparecem e os argumentos nos quais estão inseridos.

\section{Análise de Co-ocorrência e Análise de Redes}

Para contextualizar esses conceitos, eles foram, então, observados com suas relações entre si (análise de co-ocorrência, Osgood, 1959). A análise de co-ocorrência observou a ocorrência 
de cada dois conceitos na unidade da fala inteira de cada deputado. Assim, por exemplo, se um deputado citou "Deus" e "voto" durante toda a fala, entre esses dois conceitos foi contada uma co-ocorrência.

Com os conceitos observados em suas ocorrências conjuntas, é possível perceber conexões entre eles, o que apontaria para determinados conjuntos de conceitos que, juntos, poderiam delimitar sentidos frequentes aos discursos dos deputados. Para esta análise, os grupos de conceitos foram representados como redes, onde os nós são as palavras e as conexões indicam, assim, sua co-ocorrência, dentro de métricas da análise de redes. A análise de redes é uma perspectiva teórico-metodológica que auxilia na compreensão das relações entre dados em um determinado conjunto, utilizando-se de métricas específicas e da visualização através de grafos (Wasserman \& Faust, 1994; Degenne \& Forsé, 1999).

Essas métricas foram as seguintes:

1. Grau - O grau de um nó é dado pelo somatório das conexões que ele tem (Wasserman \& Faust, 1994; Degenne \& Forsé, 1999). No caso de nossa análise, os conceitos foram representados em tamanho maior ou menor a partir de sua frequência nos dados, em conexão com outros conceitos. Assim, quanto mais um conceito apareceu no discurso dos deputados, maior é sua representação.

2. Força da conexão - A aresta que conecta dois conceitos também é representada pela sua "força" (ou seja, número de vezes em que aqueles dois conceitos apareceram juntos) (Wasserman \& Faust, 1994; Degenne \& Forsé, 1999). Quanto maior a força da conexão, mais grosso é o traço que a representa. Deste modo, quanto mais dois conceitos apareceram juntos nas falas dos deputados, maior a força da conexão entre eles.

3. Modularidade - Os conceitos foram divididos a partir de um algoritmo de clusterização, ou seja, que agrupa nós "vizinhos" (que tendem a aparecer mais conjuntamente) e os divide em grupos. Esses módulos ou grupos foram representados por cores. Nesta fase, pudemos observar grupos de conceitos que tenderam a aparecer mais juntos, delimitando sentidos mais frequentes.

4. Finalmente, utilizamos um algoritmo de visualização da rede denominado Force Atlas, onde os nós com maior grau e conexões mais fortes tendem a ficar ao centro do grafo, delimitando aqueles mais fortes no corpus utilizado.

Com esses dados, obtivemos um quadro mais quantitativo dos discursos. Para observarmos de modo mais pontual e qualitativo, utilizamos ainda a Análise Argumentativa, de modo a trazer exemplos de como os sentidos foram articulados nos votos.

\section{Análise Argumentativa}

A análise argumentativa tem origem na retórica. Ela é utilizada com o objetivo de identificar o tipo de argumentação utilizado em um texto/fala. Tradicionalmente, sua base está em Aristóteles, mas diversos autores podem ser utilizados. Para este estudo, foram reunidas contribuições de quatro autores. 
1. Aristóteles descreve, em Retórica, um sistema que busca encontrar os meios mais adequados de persuasão para cada caso. Ele identifica originalmente dois tipos de argumentos: o silogismo, argumento dedutivo, e o exemplo, argumento indutivo. Além disso, aponta três provas artísticas, ou seja, as que são construídas na própria argumentação de um orador, que se diferenciam das provas inartísticas, como documentos oficias, confissões e testemunhos, por exemplo. As três provas artísticas são o ethos, o caráter do orador; o pathos, a emoção do auditório; e o logos, os elementos lógicos da argumentação. O contexto estudado por Aristóteles é bastante diferente do cenário mediatizado e da democracia representativa atual, mas seus estudos são essenciais para compreender os fundamentos da argumentação e, portanto, podem contribuir na análise proposta.

2. Fidalgo (2010) atualiza os estudos de Aristóteles para uma sociedade mediatizada. Dentre outras coisas, argumenta que o ethos se transforma em imagem, por deixar de ser um elemento intrínseco à uma argumentação isolada. Outro ponto é o fim da necessidade de copresença física entre orador e auditório, o próprio exemplo aqui analisado - a argumentação dos deputados na votação de impeachment de Dilma - mostra que oradores e auditório (ou público, segundo Fidalgo) estão separados fisicamente.

3. Chaïm Perelman (1993), no século Xx, retoma os estudos de Aristóteles para escrever o seu tratado de argumentação. A contribuição de Perelman é especialmente importante porque descreve 12 tipos de argumentos, que são divididos em três grupos: Os argumentos quase lógicos, como o próprio nome sugere, se baseiam em elementos mais lógicos e se aproximam do pensamento formal, ainda que não tenham sua natureza; os argumentos fundados sobre a estrutura do real, que se apropriam das relações entre os elementos da realidade e as utilizam para fins de determinar causa-efeito ou associação entre autor e ato; e os argumentos que fundam a estrutura do real, que são estruturados por indução, utilizando um ou mais casos específicos para generalizar. Ao descrever os argumentos em diversos tipos, Perelman facilita a identificação destes argumentos quando utilizados por um orador.

4. Anthony Weston (2009), assim como Perelman, descreve alguns tipos de argumentos. Weston busca uma aplicação prática destes argumentos, de modo que os descreve mostrando diretamente a forma como podem ser aplicados. Weston descreve cinco tipos de argumentos: exemplos, por analogia, de autoridade, sobre causas e dedutivos. Outro elemento importante descrito por Weston são as falácias, que buscam se passar por argumentos válidos, mas que, na verdade, violam alguma regra lógica. Por meio delas, é possível observar falhas argumentativas ou estratégias intencionais de persuadir um auditório por meio de um argumento não válido.

Para realizar a análise argumentativa neste estudo, optou-se por utilizar os argumentos e falácias descritos por Aristóteles, Perelman e Weston para identificar as estratégias utilizadas pelos deputados nas justificativas de seus votos. Com isto, busca-se compreender que tipo de argumento é utilizado pelos deputados. Além disso, apontar como o contexto mediatizado descrito por Fidalgo influencia neste processo persuasivo. 
Seria possível realizar uma análise específica do voto de cada deputado. O que este estudo propõe, porém, é apropriar a análise argumentativa em um método misto com a análise de conteúdo e a análise de redes. Deste modo, a partir dos grafos gerados por meio da análise de contingência e de redes referentes às justificativas de cada candidato, propõe-se uma observação de que tipos de argumentos predominaram nas falas dos deputados a favor e contra o impeachment. Assim, os votos são analisados a partir das generalizações apresentadas em cada um dos grafos, de modo que se pode compreender os padrões de votos de cada lado e, até mesmo, os que são comuns aos dois.

Para ilustrar o que é apresentado a partir da análise, optou-se por destacar algumas das falas dos deputados que demonstram a utilização dos argumentos encontrados e descritos neste estudo. O critério de seleção foi geográfico, de modo decidiu-se utilizar as falas de deputados gaúchos para ilustrar o que é construído nas análises. Na ausência de deputados que representem o Rio Grande do Sul e se apliquem aos exemplos necessários, foram selecionados deputados do estado de São Paulo, por ser o estado com o maior número de representantes na câmara, ou, caso também não exista um exemplo paulista, foram selecionados os deputados de Minas Gerais pelo mesmo critério.

\section{ANÁlise}

A questão central deste trabalho é buscar desvelar regularidades nos sentidos dos votos dos deputados, apontando quais elementos foram mais citados e quais argumentos mais utilizados pelos deputados apoiadores e contrários ao processo de impeachment. Para tanto, dividimos a análise deste modo. Em seguida, realizamos uma comparação entre os dois lados, destacando o que possuem de convergências e divergências nos argumentos utilizados.

\section{O Sim: "pelo meu estado, pelo Brasil, por Deus, pelos meus filhos, pela minha família"}

Entre os deputados presentes, 367 votaram "sim". Na Figura 1 é possível ver como foram realizados os discursos a favor do impeachment. Quanto maior o conceito, mais frequente ele é. No centro do grafo estão os que foram mais citados conjuntamente e mais afastados do centro estão os menos citados. 


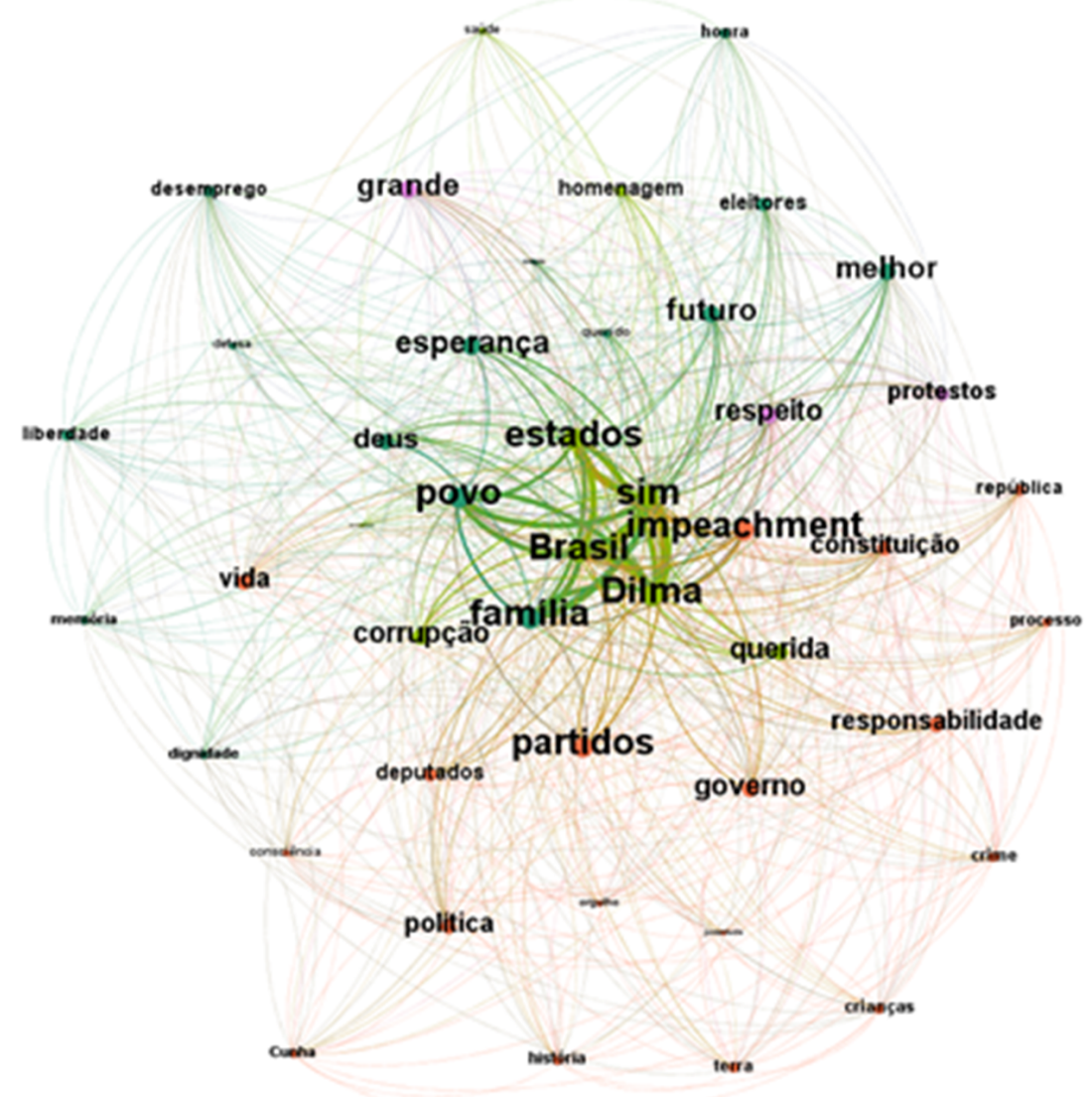

Figura 1. O discurso dos deputados que votaram "sim"

Há dois grandes núcleos, um de cor laranja e um verde. No verde, vemos os conceitos mais associados, como "povo", "estados", "sim”, "Brasill, "Dilma”, "família”, "deus", “corrupção", "esperança", "futuro". O segundo núcleo, com conceitos menos frequentes, refere-se à factualidade que supostamente basearia o impeachment, com "impeachment", "constituição", "partido", "governo", "responsabilidade". Neste contexto, temos um núcleo com um discurso mais associado a Deus, à família e ao "povo", e um núcleo associado ao "partido", "governo" e "responsabilidade".

O que se percebe é que no núcleo dos discursos estão os conceitos relacionados com seus estados de origem, com o Brasil, com o povo, e com as suas famílias. Há ainda com alta frequência a referência a Deus e aos partidos dos deputados, bem como ao fato de que representam a vontade "do povo". Observamos, assim, que as justificativas dos votos a favor do impeachment possuíam geralmente um cunho mais pessoal do que processual, visto que os conceitos que formam o grupo verde são maiores e mais centrais do que os que formam o grupo laranja. Assim, podemos encontrar, de forma quantitativa, a presença destas duas linhas na fala dos deputados. Mas como esses dados refletem a argumentação dos mesmos? 
Podemos citar primeiramente a ligação simbólica, descrita por Perelman (1993). A ligação simbólica, um dos argumentos quase lógicos, é um tipo de argumento que relaciona o símbolo com o que ele evoca. Assim, os deputados se construíam como símbolos: do seu estado, da sua família, de seus eleitores, do Brasil e, até mesmo, de Deus. Isto porque muitos dos discursos eram iniciados com estas referências: "Pelo meu estado, pela minha família, pelos meus filhos...". Os elementos pessoais - quem o deputados representa ou quer representar - se destacam mais do que os aspectos diretamente relacionados com o processo em si - a culpa ou não de Dilma do que é acusada. A maneira como os deputados fazem referência aos símbolos que representam podem ser vistas nos dois exemplos a seguir:

Afonso Hamm (PP-RS.): Em nome do povo gaúcho, povo do meu Estado, em nome do povo brasileiro, para votarmos a favor da mudança, a favor da esperança, sim ao impeachment!

Osmar Terra (PMDB-RS.): Pela minha família, minha esposa, meus filhos, pelas famílias brasileiras, pelas crianças do Brasil, pela minha Santa Rosa, meu povo do Rio Grande, pelo Brasil, é sim, Sr. Presidente!

Os exemplos acima ainda podem ser associados a outro tipo de argumento, que é construído como falácia (argumentos que violam alguma regra lógica - seriam os argumentos que buscam persuadir por meio de algum tipo de enganação ou com base em relações falsas). É o argumento/falácia ad populum (Weston, 2009). Esta falácia busca apelar para a emoção das massas está, portanto associada ao que Aristóteles chama de pathos: despertar emoções no seu auditório. Quando os deputados justificam seus votos pelo "povo", estão se apropriando deste argumento, ou seja, os deputados não estão apenas representando simbolicamente o povo, estão também realizando a vontade dele (também é possível citar o termo "protestos" como um justificativa citada pelos deputados). A falácia ad populum utilizada pelos deputados rompe com a validade de um argumento duas vezes: em primeiro lugar porque eles não podem afirmar, de fato, se o que dizem é a opinião de uma maioria, muito menos de uma totalidade do povo brasileiro; em segundo lugar, como é destacado pelo próprio Weston $(2009$, p. 97) não é válido utilizar o povo como uma fonte dotada de autoridade para tomar decisões embasadas ou imparciais, em especial na avaliação de um processo de cunho criminal.

O pathos descrito por Aristóteles não é visto apenas na utilização da falácia ad populum, mas também está presente nas falas de diversos deputados que se apropriam de termos como "esperança" e "futuro" "melhor", que também acabam relacionados com a visibilidade televisiva e a forma como este discurso emocional circula por esse meio, alterando a própria forma como o auditório/audiência recebe essa mensagem (Fidalgo, 2010). A questão da esperança pode ser vista na fala de Afonso Hamm, citada acima. Não se apresentam justificativas ou fatos para comprovar que a queda de Dilma é um meio de "esperança" para o Brasil, sequer que isso trará um "futuro melhor", mas a utilização deste tipo de promessas mexe com o auditório, gerando uma sensação de afeto ao seguimento do processo. A referência a "Deus" também aparece neste sentido, como pode ser visto nos exemplos a seguir:

Jefferson Campos (PSD-SP.): A palavra de Deus diz: Quando um justo governa, o povo se alegra. Quando um ímpio domina, o povo sofre. Pelo fim desse Governo injusto que está 
fazendo o povo sofrer, pela Nação Quadrangular no Brasil, por um pai de 78 anos que me ensinou os princípios da palavra de Deus, pelo meu Estado, eu voto sim, Sr. Presidente.

Marco Feliciano (PSC-SP): Com a ajuda de Deus, pela minha família, pelo povo brasileiro, pelos evangélicos da Nação toda, pelos meninos do MBL, pelo Vem Pra Rua Brasil - dizendo que o Olavo tem razão, Sr. Presidente, dizendo tchau para essa querida e para o PT, Partido das Trevas -, eu voto sim ao impeachment, Sr. Presidente!

O que se percebe é que a referência a Deus e a argumentação dos deputados de que seguem a vontade de Deus é propícia para despertar emoções no auditório que compartilha de uma mesma fé (genericamente se pode falar em cristã). Assim, deixa de ser o deputado que fala, mas voltando à ligação simbólica, o próprio Deus é ali representado, fazendo as paixões do auditório que concorda com a argumentação também gerar um sentimento contrário (muitas vezes de ódio) ao PT e a Dilma.

É preciso ainda destacar as falas relacionadas com os termos "responsabilidade" e "crime". No caso de "responsabilidade", é possível encontrar duas utilizações distintas: a referência ao "crime" de responsabilidade fiscal e a utilização do termo responsabilidade como justificativa de ser responsável ao escolher votar sim, isto fica claro nos exemplos abaixo.

Eduardo Barbosa (PSDB-MG.): Sr. Presidente, ao longo desses meus 6 mandatos, tenho presenciado aqui uma incoerência de um discurso humanista com uma prática inconsequente, rasteira e mentirosa. Por isso tudo e também pelo crime de responsabilidade cometido, pela honra do nosso povo mineiro e de todos aqueles que eu represento, meu voto é sim!

José Fogaça (PMDB-RS.): Que o Brasil tenha responsabilidade e sabedoria coletiva para enfrentar os momentos que virão; o voto é sim!

Guilherme Mussi (Bloco/PP-SP.): Sr. Presidente, senhoras e senhores, pela legalidade, com muita responsabilidade e serenidade, em respeito à minha família, aos meus amigos, a todos os paulistas e aos brasileiros, meu voto é sim.

O que se vê, portanto, é a presença de um silogismo simples no argumento de que o impeachment deveria prosseguir porque Dilma era culpada. O argumento modus ponens (Weston, 2009) representa esse silogismo pela forma: se a, então b; b; logo, a. A lógica é que se houve crime, deve ocorrer o impeachment; ouve crime; logo, deve ocorrer o impeachment. Porém, o que se vê é que o termo "responsabilidade" possui um tamanho intermediário no grafo e, considerando ainda que é utilizado com outros sentidos que não o de responsabilidade fiscal, pode-se aproximálo do termo "crime" para as vezes em que é utilizado com este sentido, pois apenas uma vez o termo "responsabilidade" no sentido de responsabilidade fiscal aparece sem estar ligado ao termo "crime". Observa-se que o termo "crime" é um dos menores nós no grafo, então, pode-se entender que poucas vezes o silogismo modus ponens foi, de fato, utilizado. Essas observações confirmam as análises iniciais de que a justificativa dos deputados levou em conta muito mais elementos pessoais do que processuais.

Em geral, se pode observar um posicionamento discursivo (Bourdieu, 1983) dos deputados que votaram sim baseado em questões relacionadas com os valores, em especial a questão da 
representação dos seus eleitores, de suas famílias e até mesmo de Deus. O que se vê é uma estrutura discursiva baseada em elementos pessoais, com um posicionamento contrário à Dilma e seu partido, a questão está muito mais fundamentada em ideais pessoais, como tentativa de representação simbólica, do que em elementos jurídicos que envolvem o processo.

\section{O Não: "Contra o golpe, a favor da democracia"}

O voto "não" foi realizado por 137 deputados (não foram levados em conta as abstenções para esta análise). Como pode ser visto na Figura 2, identificamos, novamente, dois grandes núcleos. Um verde, que concentra os conceitos maiores ("Dilma", "democracia", "povo", "constituição", "Brasil", "golpe", "defesa", "protestos" e "respeito", entre outros) e um roxo, que concentra conceitos menores, mas também associados, tais como "Temer", "trabalhadores", "processo", "luta", "homenagem", "família", "trabalhadores".

É interessante observar que vários dos conceitos centrais coincidem com aqueles do voto pelo "sim", mas estão associados a outros contextos. Assim, por exemplo, enquanto "Dilma" aqui aparece fortemente associado a "democracia", "defesa" e "constituição", na figura anterior, aparece associado a "querida", "governo" e "Brasil", principalmente. "Povo", aqui, está associado fortemente a "respeito", "Brasil", "constituição" e "urnas". Já na figura anterior, associa-se a "Deus", "estados", "Brasil" e "família". Ou seja, embora os conceitos sejam os mesmos, há associações diferentes em cada grafo. Há também conceitos bastante diferentes que aparecem apenas aqui e marcam a gênese dos discursos realizados pelos deputados que votaram "não": "democracia", "golpe, "respeito", "defesa" e "urnas". 


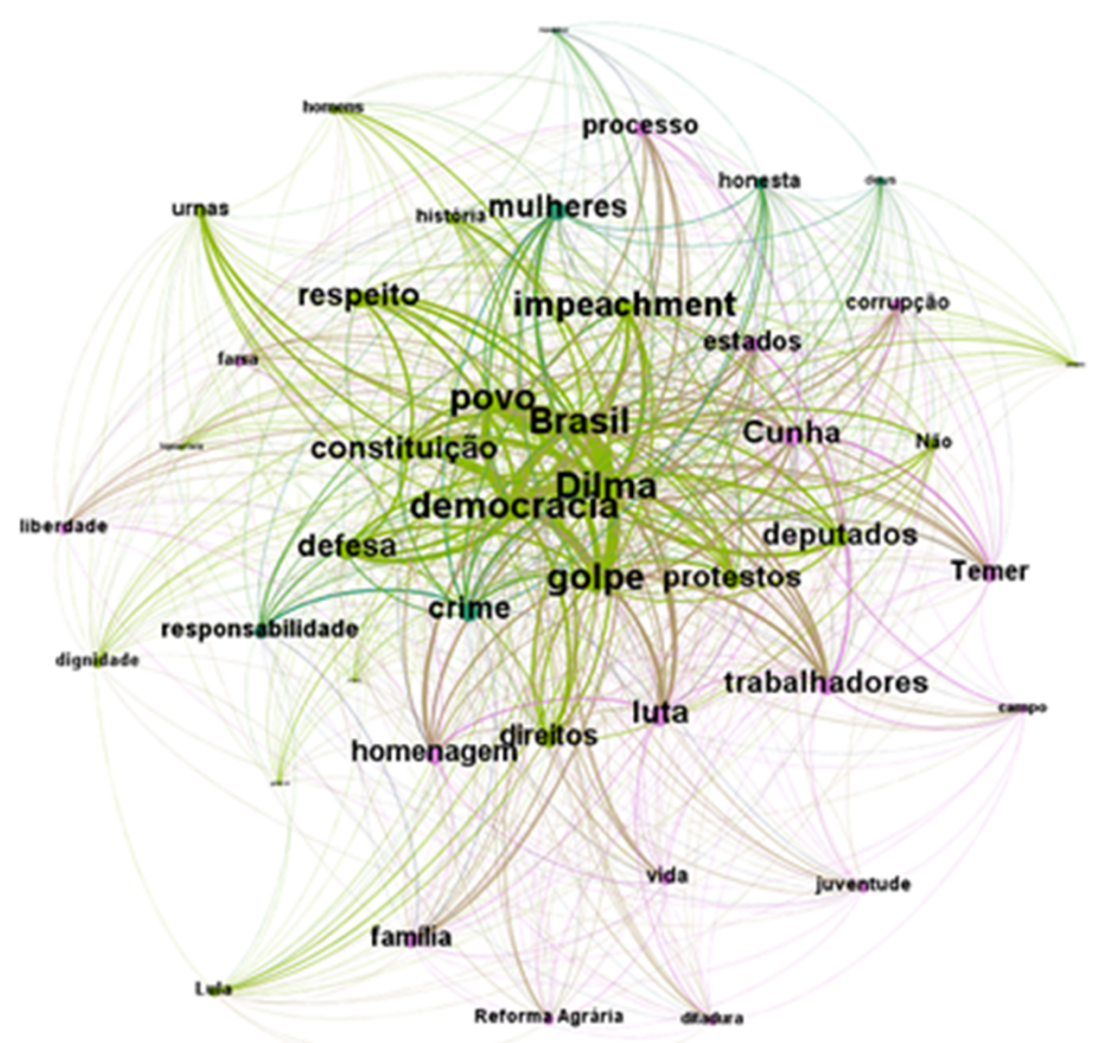

Figura 2. Conceitos dos deputados que votaram "não"

O que se percebe, então, é que o núcleo argumentativo se altera na maior parte das situações. Os deputados que votaram "não" questionam a legalidade do processo de impeachment. As justificativas, portanto, estão bem mais relacionados com elementos processuais, que apelam aos conceitos "democracia", "golpe" e "constituição" para reforçar a afirmação de ilegitimidade do processo. Algumas referências a "Cunha" também são realizadas, questionando a credibilidade do deputado para conduzir a votação e presidir a Câmara. Também se pode perceber a referência ao "povo" e ao resultado das "urnas" como argumento para a ilegalidade do processo. Isto pode ser visto nos três exemplos a seguir:

Henrique Fontana (PT-RS.): Contra a conspiração e a corrupção representadas por Eduardo Cunha e Temer; contra o golpe; em defesa da democracia e do respeito ao voto do cidadão brasileiro, eu voto com toda conviç̧ão não a esse golpe, não a esse impeachment!

Marco Maia (PT-RS.): Pelos trabalhadores e trabalhadoras do nosso Brasil, pela democracia e pelo respeito ao voto soberano do povo brasileiro, que elegeu a presidenta Dilma com 54 milhões votos, o meu voto é não a esse golpe 
Pepe Vargas (pt-rs.): Contra o acordão de Eduardo Cunha, Michel Temer e Aécio Neves, que querem abafar o combate à corrupção, contra os golpistas, que não prezam a democracia e os direitos dos trabalhadores, pela Constituição, que jurei cumprir, pela democracia e pela legalidade, meu voto é não ao golpe.

Há um argumento básico nas justificativas pelo "não": o silogismo, argumento dedutivo clássico, descrito já por Aristóteles. Ele pode ser observado pelo modus tollens (Weston, 2009), que funciona pelo modelo: Se a, então b; b é falso; logo, a é falso. Na situação analisada pode ser visto assim: Se há crime, o impeachment é legítimo; não há crime; logo, o impeachment é ilegítimo (golpe, segundo o termo utilizado pelos que defendiam Dilma). Esta é a base para a presença dos conceitos "democracia", "constituição", "golpe", dentre outros. A lógica presente neste raciocínio é que se não havia crime e o impeachment era ilegítimo (ou "golpe"), a aprovação do processo na câmara era um atentado contra a "democracia" e contra a "constituição", como pode ser observado especialmente na argumentação de Pepe Vargas. Diferente da argumentação pelo "sim" que direciona seu discurso mais ao pathos e tem maior apelação à questões televisivas, o não fundamenta suas ideias relacionadas ao logos, gerando um discurso mais complexo e que pode ter maior dificuldade de circulação em uma sociedade mediatizada (Fidalgo, 2010).

Também é possível citar a ligação de coexistência, um dos argumentos fundados sobre a estrutura do real (Perelman, 1993), quando se relaciona um indivíduo e seus atos. Ela está muito próxima do argumento em forma de falácia ad hominem (Weston, 2009). A ligação de coexistência (como argumento) ou a falácia ad hominem aparecem quando a credibilidade de Cunha é questionada, assim como quando outros nomes são citados (Temer e Aécio, por exemplo). Se Cunha não tem autoridade para presidir o processo, ele seria em sua base ilegal é a justificativa básica da argumentação. A solução entre ligação de coexistência ou falácia ad hominem se dá a partir da maneira como Cunha é considerado: se, de fato, as acusações contra ele possuem fundamento, aqui há a ligação de coexistência (como argumento real); por outro lado, se Cunha é inocente do que é acusado, então haveria apenas a falácia ad hominem. Considerando o argumento como ligação de coexistência, mais uma vez é o elemento processual que está presente nas justificativas, afinal questiona a legalidade do processo. Por outro lado, se visto como a falácia ad hominem entrariam elementos como pathos e ethos descritos por Aristóteles (Retórica) ou ainda a imagem, de Fidalgo (2010), se pensarmos em um contexto mais atual, afinal a crítica a Cunha (assim como aos outros nomes citados) busca questionar a sua credibilidade/imagem, gerando também um sentimento de revolta no auditório.

O termo "responsabilidade", ainda que sem grande destaque e mais periférico aparece no grafo também dos votos "não". O seu sentido aqui está, exceto na justificativa de um deputado, ligado com a questão do crime de responsabilidade fiscal, mais uma vez demonstrando uma relação processual nas falas. O aparecimento deste termo dá seguimento ao modus tollens já citado acima quando relacionado com os termos "democracia", "constituição" e "golpe", de modo que em algumas situações eles também aparecem. Isto pode ser visto nos dois exemplos abaixo:

Padre João (PT-MG.): Pelo respeito ao voto popular, pela Presidenta Dilma, que não cometeu nenhum crime de responsabilidade, pelos movimentos sociais, pela agricultura familiar, pela 
reforma agrária, pelo povo que está nas ruas exigindo respeito à Constituição, pelo povo latino-americano, eu voto não. E a luta continua, companheiros!

José Mentor (PT-SP.): Em respeito à Constituição e à soberania popular, em defesa da democracia, da justiça e por ser impossível um impeachment sem crime de responsabilidade; o meu voto é não.

Por fim, mais uma vez é possível citar, como nas justificativas do "sim", a ligação simbólica e a falácia ad populum, que já podem ambas ser vistas também na fala de Padre João acima destacada. Novamente os deputados se colocam como representantes simbólicos do povo, agora fazendo referências mais diretas aos "trabalhadores", às "mulheres", "reforma agrária" e, novamente, aos seus estados. Da mesma forma, ao se apropriarem da ligação simbólica, os deputados se colocam como representantes diretos daqueles que citam e das bandeiras que defendem. Isto pode ser visto nos exemplos a seguir:

Luiza Erundina (PSOL-SP.): Pelos que deram a vida pela democracia no Brasil e pelo empoderamento das mulheres, meu voto é não.

Paulo Teixeira (PT-SP): Ao povo brasileiro, "não" ao golpe daqueles que querem tirar uma pessoa que teve 54 milhões de votos nas urnas. Esses que querem tirá-la, não têm votos. Contra o ataque à Constituição e à democracia que está sendo feito aqui nesta tarde em Brasília; e contra a conspiração dirigida pelo réu por corrupção no Supremo Tribunal Federal, Eduardo Cunha, junto com Michel Temer e Aécio Neves, com o objetivo de tirar direitos do povo brasileiro, muitos deles conquistados nos Governos Lula e Dilma, voto "não", pelo Brasil!

$\mathrm{O}$ ad populum também pode ser observados nas diversas evocações aos resultados das urnas, o exemplo da justificativa de Paulo Teixeira acima destacada deixa isto bem claro. A justificativa é que se o povo elegeu Dilma, então a vontade do povo deve ser respeitada e ela deve ser mantida no seu cargo.

Quando são utilizadas as ligações simbólicas e as falácias ad populum o que se vê é que a argumentação acaba fugindo dos elementos processuais e se aproximando de justificativas pessoais ou ideológicas, como foi visto ser muito comum nas falas dos deputados a favor do impeachment. Ainda assim, é preciso destacar, como pode ser visto no grafo gerado pelas justificativas dos votos "não", os termos utilizados nas ligações simbólicas e nas falácias ad populum são, em geral, periféricos no grafo.

Se vê, de modo geral, que os deputados que votaram não, estruturaram suas falas com base em um sistema discursivo (Bourdieu, 1983) que marca suas posições. Além de se apropriarem do silogismo como base argumentativa, a qualificação do processo como "golpe" faz emanar sentidos próprios de um discurso ideologicamente marcado.

\section{Pelo sim, Pelo Não, o Que se entende?}

Após a descrição dos resultados obtidos a partir do processo metodológico baseado na análise de conteúdo, análise de redes e análise argumentativa, é possível apontar as estratégias adotadas 
por cada um dos lados no processo de votação, assim como identificar o que as argumentações possuem em comum e suas diferenças.

Os deputados que votaram "sim", em sua maioria, se apropriaram de elementos de caráter pessoal na justificativa de seus votos. A utilização deste tipo de argumento foi realizado a partir ligação simbólica (Perelman, 1993), em que os deputados se colocaram como representantes do que evocavam: de seus estados, de suas famílias, de seus eleitores, do povo brasileiro e até mesmo de Deus. Nestes casos, o elemento processual - a avaliação de um processo criminal - não era levada em conta. Em muitos casos também foi utilizada a falácia ad populum (Weston, 2009) para se referir à vontade do povo na retirada de Dilma do seu cargo. Também aqui não é levado em conta o caráter jurídico do processo, mas elementos pessoais (Dilma deve sair porque o povo quer), resultando em dois problemas: 1) os deputados não são capazes de comprovar se a retirada de Dilma do poder seria, de fato, a vontade do povo e; 2) como caráter problemático próprio da falácia ad populum, utilizar a vontade do povo como base argumentativa não tem validade porque não há autoridade deste na tomada de decisões de forma imparcial (Weston, 2009), em especial quando se trata de um processo criminal, onde se pressupõe a necessidade de uma especialização na área para a eficiência na avaliação do caso.

Em alguns casos, os deputados que votaram "sim" também se referem ao caráter processual do impeachment, utilizando o modus ponens (Weston, 2009) como modelo argumentativo. Deste modo, afirmam que a retirada de Dilma da presidência seria necessária, considerando que houve crime durante o seu mandato. Este tipo de argumentação, porém, é minoria entre os deputados, como pode ser observado quantitativamente na figura 1 - em que os termos "responsabilidade" e, principalmente, "crime" (que melhor representa no grafo este tipo de argumento) estão posicionados em espaços periféricos e "crime" está entre os menores termos do grafo.

Os deputados que votaram não, por sua vez, tomaram a questão processual como elemento central de argumentação. Ao denominar como "golpe" (central na figura 2, assim como "democracia", "constituição" e "crime") o processo de impeachment sem a realização de qualquer crime por parte de Dilma, os deputados utilizam como formato argumentativo o modus tollens (Weston, 2009) para afirmar que como não houve crime, o processo seria ilegal. Em sentido próximo, a questão de legalidade do processo como um todo também é colocada em questão, especialmente por críticas a Eduardo Cunha, então presidente da câmara e responsável por conduzir a votação. Para isto, foi utilizada a ligação de coexistência (Perelman, 1993), em uma aproximação tênue com a falácia ad hominem (Weston, 2009), para questionar a credibilidade de Cunha para presidir o processo, inserindo no debate a imagem (Fidalgo, 2010) do político, de modo que o ethos (Aristóteles, Retórica) é colocado como tema central na discussão.

Assim como os deputados favoráveis ao processo de impeachment, ainda que com menor centralidade, os deputados que votaram "não" também utilizaram a ligação simbólica (Perelman, 1993) e a falácia ad populum (Weston, 2009). No caso da primeira, os deputados evocaram principalmente seus estados, o povo em geral e bandeiras ideológicas (como "mulheres", "trabalhadores" e "reforma agrária"), marcando, assim, o seu posicionamento em um campo ideológico de fala (Bourdieu, 1983). No caso da falácia ad populum, os deputados que votaram "não" usam como base argumentativa a eleição de Dilma a partir do voto popular, aproximando a argumentação de um formato válido, ainda que, assim como os que votaram a favor do processo, não possam 
confirmar que esta é a opinião do povo ou defender um posicionamento especializado a partir da opinião pública.

O que se pode inferir, portanto, é que, no geral, os dois lados utilizaram o argumento/falácia $a d$ populum, justificando que estavam seguindo a vontade do povo, para retirar Dilma de seu cargo (no caso do "sim") ou para manter a voz das "urnas" e não permitir o "golpe" contra a "democracia" (no caso do "não"). Da mesma forma, ambos também se apropriaram de argumentos válidos. O direcionamento destes argumentos, porém, foi diferente. No caso do "sim", na maioria das vezes eram ligações simbólicas que evocavam elementos pessoais, enquanto no "não" se observava o silogismo modus tollens e a ligação de coexistência para questionar elementos referentes ao processo em si.

A base central das justificativas de cada um dos lados, porém, foi diferente. Os argumentos do "sim" estavam mais vinculados a elementos pessoais (como fica claro quando falam em família e Deus), evocando também elementos relacionados ao pathos (Aristóteles, Retórica) como a esperança por um futuro melhor. Por outro lado, os argumentos dos votos "não" traziam referências mais diretas ao processo do impeachment, questionando o próprio processo e também Cunha, responsável pela sua condução, podendo ser observado no silogismo modus tollens, que defende a ilegalidade do processo. A observação isolada do termo "responsabilidade" nos grafos do "sim" e do "não" serve para demonstrar a afirmação anterior, enquanto no "sim" muitas vezes era utilizada apenas como a ideia de ser responsável, não fazendo referência ao crime de responsabilidade fiscal, no "não" este era o seu sentido, com a exceção de apenas um caso.

É possível verificar que, apesar de se apropriarem de argumentos distintos em algumas situações, os votos foram marcados por posições relacionadas com a questão política como um todo. Partindo das ideias de Bourdieu (1983) sobre o discurso político e o poder simbólico, é possível identificar duas correntes ideológicas, que produzem seus discurso a partir de posições que ocupam, ainda se apropriem de elementos específicos para justificar seus votos. A questão, acima de quem tem razão sobre o processo, é o embate simbólico que ocorre entre os dois lados.

\section{CONSIDERAÇões Finais}

Este estudo tinha como objetivo analisar os elementos argumentativos nas justificativas dos deputados na primeira votação que ocorreu em relação ao processo de impeachment de Dilma Rousseff. Para tal, a retórica (Aristóteles, Retórica; Perelman, 1993; Fidalgo, 2010) foi utilizada como base teórica, assim como as relações com o poder simbólico (Bourdieu, 1983). O processo metodológico se deu a partir de três eixos: análise de conteúdo, análise de redes e análise argumentativa.

Por meio da análise realizada, foi possível identificar que a base argumentativa dos deputados que votaram "sim" e "não" partiram de elementos distintos, relevando que posicionavam-se também em posições ideológicas diferentes (Bourdieu, 1983). Os deputados que votaram "sim" tomaram, majoritariamente, como foco questões pessoais - se referindo, por exemplo, às suas famílias, aos seus estados e a Deus. Os deputados que votaram "não", por outro lado, colocaram, em sua maioria, o processo avaliado como centro de suas justificativas, chamando de "golpe" a tentativa de tirada de Dilma do poder sem que houvesse comprovação do crime que era acusada. 
Dentre os argumentos utilizados, os dois lados se apropriaram da falácia ad hominem (Weston, 2009), assim como da ligação simbólica (Perelman, 1993). Este inclusive, foi o principal argumento utilizado pelos deputados que votaram "sim", que também se apropriaram da modus ponens (Weston, 2009) nas poucas ocasiões em que se referiram ao processo julgado. Já os deputados que votaram "não" utilizaram o modus tollens (Weston, 2009) como principal justificativa para a irregularidade do impeachment, assim como a ligação de coexistência (Perelman, 1993) direcionada principalmente ao deputado Eduardo Cunha (responsável por presidir a votação) para questionar a legalidade do processo como um todo.

\section{REFERÊNCIAS}

Aristóteles (2005). Retórica. 2 ed. (trad. M. Alexandre Júnior, P. F. Alberto \& A. do N. Pena). Lisboa: Imprensa Nacional-Casa da Moeda.

Bardin, L. (2003). Análise de Conteúdo. Lisboa: Ed. 70.

Bourdieu, P. (1983). Language and Symbolic Power (trad. G. Raymond \& M. Adamson). Cambridge, MA: Harvard UniversityPress.

Degenne, A. \& Forsé,M. (1999). Introducing Social Networks. London: Sage Publications.

Fidalgo, A. (2010). Da retórica às indústrias da persuasão. In I. Ferreira \& G. Gonçalves (org.), As Indústrias da Persuasão (pp. 5-25). Covilhã: Livros Labcom.

Osgood, C. (1959). The representational model and relevant research methods. In I. de S. Pool, Trends in Content Analysis. Urban: Univ. of Illinois Press.

Perelman, C. (1993). O Império Retórico: Retórica e Argumentação (trad. F. Trindade \& R. A. Grácio). Porto: Asa.

Recuero, R.; Bastos, M. \& Zago, G. (2015). Análise de Redes para Mídia Social. Porto Alegre: Sulina.

Van Dijk, T. A. (2002). Political discourse and ideology. In C. U. Lorda \& M. Ribas (org.), Anàlisi del discurs polític: Producció, mediació i recepció (pp. 15-34). Barcelona: Universitat Pompeu Fabra, Institut Universitari de Lingüística Aplicada (IULA).

Wasserman, S. \& Faust, K. (1994). Social Network Analysis: Methods and Aplications. Cambridge: Cambridge University Press.

Weston, A. (2009). A construção do argumento (trad. A. F. Rosas). São Paulo: Editora WMF Martins Fontes. 